\title{
LEVANTAMENTO FLORÍSTICO DA MATA CILIAR URBANA DO CÓRREGO ÁGUA TURVA EM DOIS VIZINHOS-PR
}

\author{
FLORISTIC SURVEY OF URBAN RIPARIAN FOREST OF "AGUA TURVA" \\ STREAM IN DOIS VIZINHOS - PR
}

\begin{abstract}
Suzamara Biz¹, Tamara Ribeiro Botelho de Carvalho Maria², Clézio José Mota³ Flávia Gizele König Brun ${ }^{5}$, Eleandro José Brun ${ }^{6}$
\end{abstract}

\begin{abstract}
RESUMO
Objetivou-se com o presente trabalho realizar o levantamento florístico nas margens do Córrego Água Turva localizado no município de Dois Vizinhos-PR. Para o estudo delimitou-se a parte urbana do córrego onde foram identificados por meio de censo todos os indivíduos encontrados na mata ciliar do córrego que, segundo a legislação vigente no período de estudo (Lei 7.511 de 1986), inclui-se toda a vegetação encontrada a uma distância de até 30 metros das margens. Foram identificadas 38 famílias, um total de 738 indivíduos, sendo que entre estes, 663 são exóticos dos quais 419 são exóticos com potencial invasor e apenas 75 são nativos. A família Oleaceae apresentou a maior dominância correspondente a $13,0 \%$ do total, não havendo diversidade botânica, sendo representada exclusivamente pelas espécies Ligustrum lucidum, que possui potencial invasor, assim como a Leucena leucocephala e Hovenia dulcis (11,9\%). O manejo e planejamento da mata no entorno do córrego deve levar em consideração a grande quantidade de espécies invasoras encontradas, que interferem na flora e fauna local.
\end{abstract}

Palavras-chave: Exóticas; Áreas de preservação permanente; Vegetação.

\section{ABSTRACT}

The objective of this study was survey the flora on the margins of Água Turva Stream in the municipality of Dois Vizinhos-PR. For the study, the urban part of the stream was delimited, where there were identified through census all the individuals found in the riparian areas of the stream which, according to current legislation in the study period (Law 7511 of 1986), includes all vegetation found at a distance of 30 meters from the margins. There was identified 38 families, a total of 738 individuals, and of these, 663 are exotic of which 419 are exotic with invasive potential and only 75 are native. The Oleaceae family had the highest dominance corresponding to $13.0 \%$ of the total, with no botanical diversity, being represented only by the species Ligustrum lucidum, which has invasive potential, as well as Leucaena leucocephala and Hovenia dulcis (11.9\%). The management and planning of the riparian vegetation should take into account the large number of invasive species found, which affect the local flora and fauna.

Keywords: Exotic; Permanent preservation areas; Vegetation.

Recebido em 24.06.2015 e aceito em 13.10.2015

1 Engenheira Florestal, Mestranda em Agronomia, Universidade Estadual do Centro-Oeste, Guarapuava/PR. E-mail: suzamarabiz@gmail.com

2 Engenheira Florestal, Mestranda em Engenharia Florestal, Universidade Federal do Paraná, Curitiba/PR. E-mail: trbotelhomaria@gmail.com

3 Engenheiro Florestal, Integrante do grupo de Silvicultura Urbana da Universidade Tecnológica Federal do Paraná, Dois Vizinhos/PR. E-mail: cleziomota_nucleonativa@outlook.com

4 Engenheiro Florestal, Universidade Tecnológica Federal do Paraná, Dois Vizinhos/PR. E-mail: jeanfelipef@hotmail.com

5 Engenheira Florestal, Dra., Professora e coordenadora do grupo de Silvicultura Urbana da Universidade Tecnológica Federal do Paraná, Dois Vizinhos/PR. E-mail: flaviagbrun@gmail.com

6 Engenheiro Florestal, Dr. Professor e coordenador do grupo PET Engenharia Florestal da Universidade Tecnológica Federal do Paraná, Dois Vizinhos/PR. E-mail: eleandrobrun.utfpr@gmail.com 


\section{INTRODUÇÃO}

O ritmo acelerado da urbanização das cidades gerou muitas modificações no ambiente. A diminuição das florestas e a fragmentação das mesmas no meio urbano se tornou algo comum para o estabelecimento de estruturas urbanas diversas.

Como consequência da ausência de planejamento do desenvolvimento urbano, boa parte da cobertura vegetal, de áreas nativas e matas ciliares, foram completa ou parcialmente destruídas ou degradadas, ocasionando uma grande perda da biodiversidade, da qualidade das águas e da qualidade ambiental, antes preservada pela vegetação.

Segundo Ferreira e Dias (2004), nunca, em toda a história da humanidade, a utilização dos recursos naturais foi tão questionada como nos dias atuais, proporcionando o aumento da consciência ecológica de recuperação dos ecossistemas degradados pelo homem, para que estes se aproximem ao máximo de sua estrutura natural.

Como são múltiplos os benefícios da vegetação ciliar para os ambientes onde ocorrem principalmente nas áreas urbanas, torna-se indispensável que o poder público promova ações conjuntas de preservação, restauração e medidas mitigadoras de impactos, especialmente no que diz respeito à conscientização da população por meio de programas de educação ambiental (BAILLY et al., 2012).

A importância das matas ciliares está na alimentação e refúgio da biota aquática e terrestre, além de servir como corredor ecológico e preservação das margens contra assoreamento e erosões do solo, sendo ainda, indispensáveis na manutenção da qualidade da água dos mananciais e do fluxo gênico entre as comunidades próximas (LACERDA; FIGUEIREDO, 2009; BAILY et al., 2012).

No entanto, para o desenvolvimento de um plano de manejo com a finalidade de se garantir a conservação desse tipo de fragmento vegetal, que é de extrema importância para a qualidade de vida da população urbana, é fundamental o desenvolvimento de estudos que analisem a dinâmica dessas matas, os efeitos da interface humana no local e os efeitos da invasão de espécies oportunistas (ROSA; SCHIAVINI, 2006).

Oliveira e Amaral (2004) enfatizam a importância dos estudos florísticos e fitossociológicos das florestas, devido à sua contribuição para a conservação e preservação da diversidade, permitindo-se conhecer o estado atual dos fragmentos para a elaboração de possíveis planos de recuperação.

Sendo assim, a análise da estrutura horizontal destes fragmentos deverá quantificar a participação de cada espécie em relação às outras e verificar a forma de distribuição espacial de cada espécie. Outra informação importante a ser obtida são os índices de 
diversidade, que podem ser determinados pelo índice de diversidade Shannon-Weaver $\left(\mathrm{H}^{\prime \prime}\right)$ e o índice de uniformidade de Pielou (J").

Com o exposto, objetivou-se com o presente trabalho realizar o levantamento florístico da mata ciliar do Córrego Água Turva localizado na área urbana do município de Dois Vizinhos-PR, identificando as espécies e avaliando as características de densidade e índices de diversidade do local.

\section{MATERIAL E MÉTODOS}

\section{Descrição da área de estudo}

O levantamento florístico foi realizado nas margens do Córrego Água Turva, especificamente no trecho onde o córrego passa pela área urbana do município localizada na microbacia hidrográfica do Rio Jirau Alto, no município de Dois Vizinhos - PR (Figura 1).

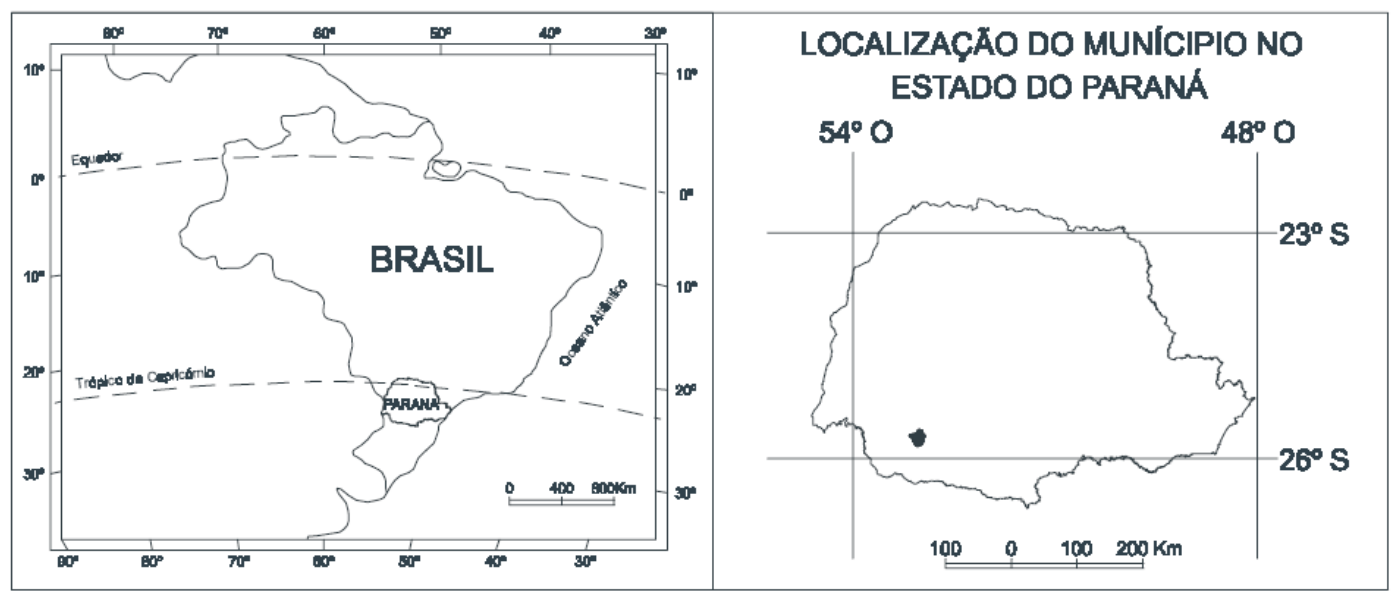

Figura 1. Localização do município de Dois Vizinhos no Estado do Paraná

Figure 1. Localization of Dois Vizinhos in Paraná state

O município está inserido no terceiro planalto paranaense, sob as coordenadas $25^{\circ}$ $44^{\prime} 03^{\prime \prime}$ e $25^{\circ} 46^{\prime} 05^{\prime \prime}$ Sul e $53^{\circ} 03^{\prime} 01^{\prime \prime}$ e $53^{\circ} 03^{\prime} 10^{\prime \prime}$ Oeste, apresentando uma altitude média de 500 metros e presença de encostas relativamente íngremes, com declividade superior a 20\% (JUNG, 2013).

O clima é classificado como subtropical úmido mesotérmico (Cfa), de verões quentes, geadas pouco frequentes e chuvas com tendência de concentração nos meses do verão (ALVAREZ et al., 2013).

O Córrego Água Turva (Figura 2), assim como os demais corpos d'água do município, estão inseridos na bacia hidrográfica do rio Iguaçu, podendo ser encontrados no perímetro urbano também os rios Dois Vizinhos e Jirau Alto (JUNG, 2013). 


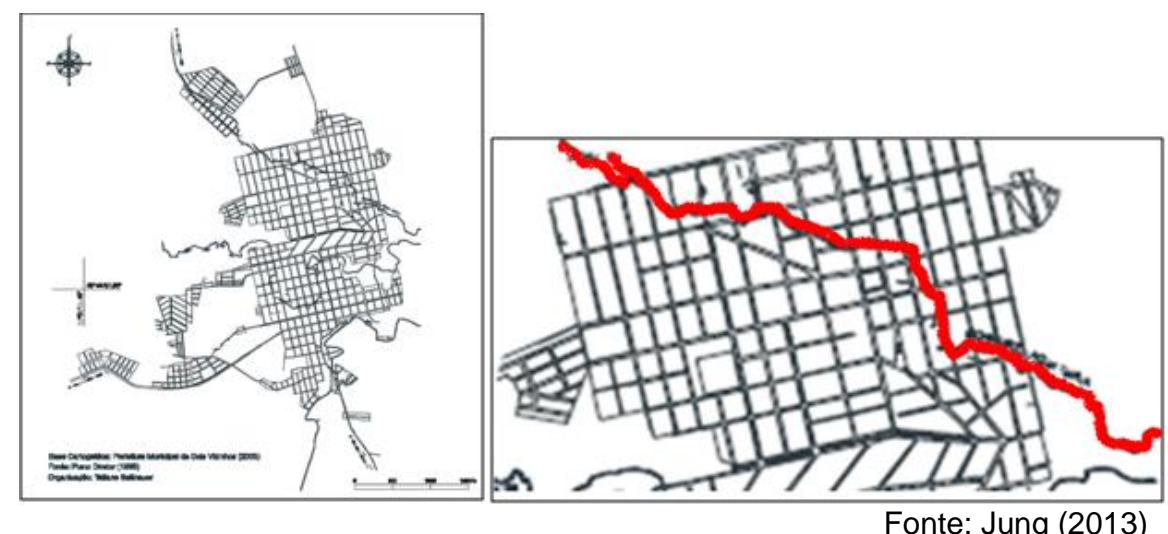

Figura 2. Malha urbana da cidade de Dois Vizinhos e Localização do Córrego Água turva Figure 2. Urban area of Dois Vizinhos and Location of Água Turva stream

Segundo Jung (2013) o córrego Água Turva apresenta duas nascentes principais, uma localizada no Bairro Margarida Galvan e outra na zona rural do município, com forte expansão urbana. Essas nascentes se unem no início do Bairro da Luz, percorrendo a seguir, os Bairros Centro Norte, das Torres e áreas agrícolas, desaguando no rio Jirau Alto. No transcurso do córrego Água turva, percebe-se a supressão da área ciliar pela expansão imobiliária (Figura 3A e 3B), agrícola e por assentamentos irregulares, causando processos erosivos (Figura 3C e 3D), desmatamento e despejo de esgoto e lixo.
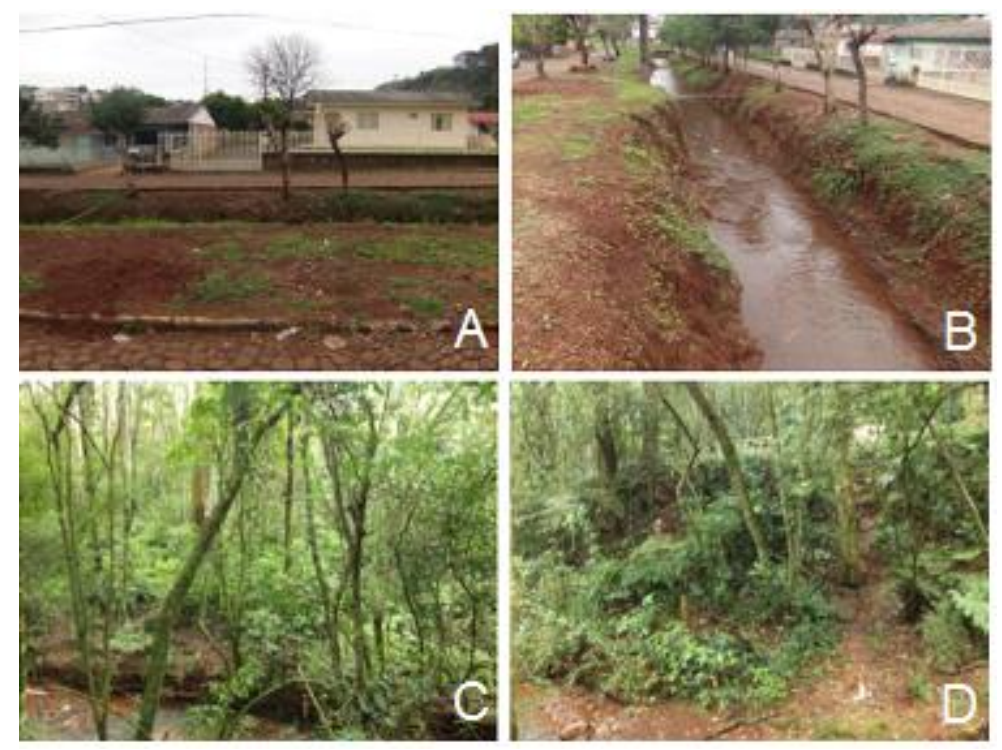

Fonte: Jung (2013)

Figura 3. Fragmentos do córrego Água Turva em Dois Vizinhos PR. A e B, supressão da mata ciliar pela expansão urbana, $\mathrm{C}$ e $\mathrm{D}$, processos erosivos

Figure 3. Fragments of Agua Turva stream in Dois Vizinhos PR. A and B, suppression of riparian vegetation by urban sprawl, $C$ and $D$, erosive processes 


\section{Metodologia}

Para a realização do levantamento florístico delimitou-se o trecho em que o córrego passa pela área urbana do município, ou seja, a parte urbana do córrego, onde foram coletados alguns pontos para que fosse possível a determinação do comprimento deste trecho. Os pontos foram obtidos pelo uso do GPS de navegação Garmin modelo Etrex, com transferência de dados para o aplicativo Google Earth $\AA$, sendo obtida a extensão da mata ciliar urbana em estudo, estimada em, aproximadamente, 3.700 metros.

O levantamento florístico foi realizado por meio de censo, avaliando todos os indivíduos arbóreos que apresentassem mais de 2 metros de altura que se encontravam a uma distância de 30 metros de ambas as margens do córrego, conforme a Lei 7.511, de 1986, vigente no período do estudo.

Entretanto, devido à alta urbanização e degradação da área de APP encontrada no entorno do córrego, a vegetação da mata ciliar foi encontrada até uma distância média de 10 metros das margens, variando para uma distância menor conforme o aumento da urbanização, chegando à áreas onde foi canalizado.

No levantamento foi realizada a identificação das espécies a campo. Os exemplares que não foram de passível identificação em campo, tiveram material botânico coletado para posterior identificação com auxílio de literatura especializada.

Os dados obtidos em campo foram tabulados em planilha eletrônica Microsoft Office Excel® quanto às espécies e o número de indivíduos de cada espécie. Foram obtidos por meio de revisão bibliográfica os dados de família botânica, origem e potencial de invasão das espécies exóticas. Foram também calculados os valores de densidade relativa, densidade absoluta, índice de diversidade de Shannon e índice de impacto de exóticas.

A densidade das espécies que denota o número de indivíduos da espécie "i" por unidade de área e sua forma relativa em função do número total de indivíduos foi obtida pela seguinte equação.

$$
\begin{gathered}
D A=n / \text { ha } \\
D R=D A / N * 100
\end{gathered}
$$

Onde:
$\mathrm{DA}=$ densidade absoluta (Ind.ha-1);
$\mathrm{DR}=$ densidade relativa (\%);
$\mathrm{n}$ = número de indivíduos da espécie “i”;
$\mathrm{N}=$ número total de indivíduos. 
O índice de diversidade de Shannon foi utilizado para mensurar a diversidade da vegetação na área de estudo, obtido pela seguinte equação:

$$
H^{\prime}=\Sigma s i=1(n i / N){ }^{*} \ln (\mathrm{ni} / \mathrm{N})
$$

Onde:

$\mathrm{H}^{\prime}$ = Índice de Diversidade de Shannon;

ni = número de indivíduos amostrados para a i-ésima espécies;

$\mathrm{N}$ = número total de indivíduos amostrados;

Ln = Logaritmo Neperiano .

Através deste índice também foram mensurados os dados de equabilidade de Pielou para determinar a homogeneidade ou heterogeneidade da mata ,obtido por:

$$
J^{\prime}=H^{\prime} / H^{\prime} \max
$$

Onde:

J' = Índice de Uniformidade de Pielou;

$\mathrm{H}^{\prime}=$ Índice de diversidade real;

H' max = Diversidade máxima.

\section{RESULTADOS E DISCUSSÃO}

Foram encontrados 738 indivíduos arbóreos distribuídos em 38 famílias botânicas, 55 gêneros e 59 espécies. Destes, 244 indivíduos são de origem exótica (33\%), 75 de origem nativa (10\%) e 419 de origem exótica com potencial invasor (57\%).

A grande percentagem de exóticas invasoras às margens do córrego (57\%) também foi encontrada por Oliveira et al. (2012), que justifica a ocorrência em grande quantidade dessas espécies devido à atração dos seus frutos pela avifauna facilitando a dispersão de suas sementes.

Algumas espécies exóticas podem ter sido introduzidas por moradores do entorno do córrego, que por falta de conhecimento técnico, plantaram os indivíduos arbóreos que atendessem ao seu interesse, estético ou funcional, e que fossem de mais fácil aquisição.

As espécies exóticas invasoras podem interferir na reabilitação das matas ciliares, pois são capazes de dominar as áreas onde se estabelecem. Além da dispersão das sementes, outro fator relevante para o estabelecimento das exóticas pode ser a falta de inimigos naturais no ambiente urbano, pois o processo de antropização normalmente promove o desequilíbrio ambiental (PINHEIRO; RIBEIRO, 2001). 
Devido a grande quantidade de espécies exóticas com potencial invasor é necessário que sejam realizadas ações de manejo, com a finalidade de substituição destas espécies por outras de origem nativa, pois, conforme Araújo et al. (2009) a falta de manejo destas áreas diminui as chances de as espécies nativas se perpetuarem a longo do tempo. Desta forma, a vegetação ciliar necessita de um plano de manejo participativo, que envolva a erradicação de espécies exóticas e enriquecimento da área com espécies nativas, especialmente por se encontrarem dentro da zona urbana.

Blum et al. (2008) relatam que as espécies exóticas com agressivo potencial invasor acarretam alteração das comunidades florestais da região. Esse fato já está sendo observado, sendo que as exóticas invasoras tendem a ocupar o espaço de espécies nativas provocando desequilíbrios ecológicos e, em médio ou longo prazo, redução na biodiversidade local.

Quando avaliadas as famílias botânicas, observou-se o predomínio das famílias Oleaceae (13\%), Fabaceae (12,46\%), Rhamnaceae (11,92\%), Rutaceae (10,16\%), Euphorbiaceae e Rosaceae (8,13\%).

Pode-se observar a dominância da família Oleaceae, com 96 indivíduos (13\%), representados por uma única espécie Ligustrum lucidum W.T.Ait. (alfeneiro), de caráter exótico invasor. A mesma espécie foi apresentada como dominante no município de Mangueirinha - PR, onde a espécies representou 47\% dos indivíduos amostrados na arborização urbana (SCHALLENBERGER; MACHADO, 2013).

Vigiliato e Zampar (2011), afirmam que espécies que apresentam dispersão zoocórica, como o caso do Ligustrum lucidum, tem sua invasão potencializada. Segundo Schallenberger e Machado (2013) a espécie é resistente a pragas e doenças e pouco exigente nutricionalmente.

A família Fabaceae, apresentou 92 indivíduos, correspondendo a aproximadamente $12,43 \%$ dos indivíduos totais, estando representada por 5 espécies: Tipuana tipu (benth.) kuntze (tipuana), Leucaena leucocephala (Lam.) R. de Wit. (leucena), Parapiptadenia rígida (Benth.) Brenan (angico), Peltophorun dubium Spreng.) Taub. (sibipiruna) e Bauhinia forticata Link. (pata-de-vaca). A mesma família foi a de maior ocorrência em vegetação ripária de caatinga em Pernambuco (SOUZA; RODAL, 2010), em vegetação ripária do rio Alto Paraná, no município de Porto Rico - PR (SOUZA; MONTEIRO, 2005) e em Sergipe (FERREIRA et al., 2011)

A Leucaena leucocephala, foi a terceira espécie de maior ocorrência, e segundo o Instituto Ambiental do Paraná (IAP, 2009), apresenta caráter invasor. Pertencente à família Fabaceae, a Leucaena leucocephala foi a espécie mais expressiva dentro de sua família, sendo representada por 67 indivíduos. 
A família Rhamnaceae, registrou a ocorrência de 88 indivíduos, correspondendo a $11,9 \%$ do total levantado. Todos os indivíduos analisados desta família são da espécie Hovenia dulcis Thunb. (uva-do-japão), exótica com potencial invasor, segundo o IAP (2009). A Hovenia dulcis é uma das espécies que tem facilidade de dispersão em áreas ripárias, formando um sub-bosque homogêneo nestas regiões e impedindo o desenvolvimento das espécies nativas (SAMPAIO et al., 2011). Essa espécie se assemelha, no potencial agressivo de dominância, à espécie Leucaena leucocephala, fazendo-se necessário sua substituição gradativa por espécies naturais do ecossistema, pois quando existe em grande quantidade acarreta desequilíbrio ambiental, e a médio e longo prazos, a perda drástica da biodiversidade local (ZALBA, 2006).

A família Rutaceae, apresentou um total de 75 indivíduos (10,1\%), todos do gênero Citrus, sendo eles: Citrus aurantium L. (laranja), Citrus reticulata Blanco (laranja), Citrus sinensis (L.) Osbeck (laranja), Citrus x limonia (L.) Osbeck (limão). Dentre as espécies do gênero Citrus, apenas a espécie Citrus reticulata é nativa, sendo esta representada por apenas 12 indivíduos.

Há a ocorrência de 16 indivíduos da espécie Citrus aurantium, espécie exótica e invasora, cuja dispersão, em sua maioria, se da por barocoria, o que explica a grande quantidade de indivíduos próximos, ou seja, a dispersão em grandes distâncias é dificultada. Porém, segundo Santana e Encinas (2008), em menores proporções pode ocorrer a dispersão por zoocoria.

As demais espécies Citrus sinensis (22 indivíduos) e Citrus x limonia (25 indivíduos) são de origem exótica, entretanto, não apresentam potencial invasor. A presença acentuada nas margens do córrego deve-se ao uso e apreciação dos frutos por parte dos moradores próximos, que possivelmente tenham plantado as mesmas nesses locais.

Da família Euphorbiaceae ocorreram 60 indivíduos da espécie Ricinus communis L. (mamona) (8,1\%), sendo esta classificada como espécie exótica invasora pelo IAP (2009).

A família Rosacea foi representada pelas espécies Eriobothrya japônica (Thunb.) Lindl. (nêspera), Pyrus communis L. (pêra), Prunus myrtifolia L.Urb. (pessegueiro-bravo), Rubus sellowii Cham. \& Schltdl. (amorinha-preta), sendo a primeira classificada como invasora (IAP, 2009) e representada por 26 indivíduos (Tabela 1).

O índice de diversidade de espécies de shannon, obtido foi de 3,25. Este pode ser considerado alto quando relacionado ao índice máximo de diversidade, de 4,077. Este índice determina o bem-estar do ecossistema, sendo assim quanto maior o valor encontrado maior o valor ecológico em questão. 
Tabela 1. Espécies inventariadas, segundo o número de indivíduos, densidade absoluta (DA), densidade relativa (DR) para a mata ciliar do córrego Água Turva

Table 1. Sampled species, its respective quantity, absolute density, relative density for the riparian forest of Agua Turva stream

\begin{tabular}{|c|c|c|c|c|c|}
\hline Nome científico & $\begin{array}{l}\text { Nome } \\
\text { popular }\end{array}$ & Família & Quant. & DA & DR \\
\hline Annona squamosa L. & Araticum & Annonaceae & 5 & 1.470 .588 & 0.677507 \\
\hline Araucaria angustifólia (Bertol.) Kuntze & Araucária & Araucariaceae & 6 & 1.764 .706 & 0.813008 \\
\hline Bacaris dracunculifolia DC. & Vassoura & Asteraceae & 2 & 0.294118 & 0.135501 \\
\hline Bambusa vulgaris Schrad. ex J.C. Wendl & Bambu & Poaceae & 1 & 0.294118 & 0.135501 \\
\hline Bauhinia forficata Link. & $\begin{array}{l}\text { Pata-de- } \\
\text { vaca }\end{array}$ & Fabaceae & 2 & 0.588235 & 0.271003 \\
\hline $\begin{array}{l}\text { Brugmansia suaveolens (Willd.) Bercht. \& J. } \\
\text { Presl. }\end{array}$ & Trombeteiro & Solanaceae & 6 & 1.764 .706 & 0.813008 \\
\hline Camellia japonica H. Lév & Camélia & Theaceae & 2 & 0.588235 & 0.271003 \\
\hline Campomanesia xanthocarpa Berg & Guabiroba & Myrtaceae & 1 & 0.294118 & 0.135501 \\
\hline Capsicum annuum L. & Pimenta & Solanaceae & 3 & 0.882353 & 0.406504 \\
\hline Carica papaya L. & Mamão & Caricaceae & 8 & 2.352 .941 & 1.084 .011 \\
\hline Casearia sylvestris Sw. & $\begin{array}{l}\text { Chá-de- } \\
\text { bugre }\end{array}$ & Salicaceae & 1 & 0.294118 & 0.135501 \\
\hline Ceiba speciosa (A.St.-Hil.) Ravenna & Paineira & Bombacaceae & 1 & 0.294118 & 0.135501 \\
\hline Citrus aurantium L. & Laranja & Rutaceae & 16 & 4.705 .882 & 2.168 .022 \\
\hline Citrus reticulata Blanco & Laranja & Rutaceae & 12 & 3.529 .412 & 1.626 .016 \\
\hline Citrus sinensis (L.) Osbeck & Laranja & Rutaceae & 22 & 6.470 .588 & 298.103 \\
\hline Citrus $x$ limonia (L.) Osbeck & Limão & Rutaceae & 25 & 7.352 .941 & 3.387 .534 \\
\hline Cordia americana (L.) Gottshling \& J.E.Mill. & Guajuvira & Boraginaceae & 1 & 0.294118 & 0.135501 \\
\hline Cupressus sempervirens L. & Cipreste & Cupressus & 2 & 0.588235 & 0.271003 \\
\hline Duranta repens L. & $\begin{array}{l}\text { Pingo-de- } \\
\text { ouro }\end{array}$ & Verbenaceae & 2 & 0.588235 & 0.271003 \\
\hline Eriobotrya japonica (Thunb.) Lindl. & Nêspera & Rosaceae & 26 & 7.647 .059 & 3.523 .035 \\
\hline Eucalyptus sp. & Eucaliptus & Myrtaceae & 6 & 1.764 .706 & 0.813008 \\
\hline Eugenia involucrata DC. & Cereja & Myrtaceae & 4 & 1.176 .471 & 0.542005 \\
\hline Eugenia uniflora L. & Pitanga & Myrtaceae & 7 & 2.058 .824 & 0.948509 \\
\hline Ficus benjamina L. & Ficus & Moraceae & 3 & 0.882353 & 0.406504 \\
\hline Grevillea robusta A. Cunn & Grevilea & Proteaceae & 5 & 1.470 .588 & 0.677507 \\
\hline $\begin{array}{l}\text { Handroanthus chrysotrichus (Mart. Ex. A. } \\
\text { DC.) Mattos }\end{array}$ & Ipê-Amarelo & Bignoniaceae & 2 & 0.588235 & 0.271003 \\
\hline Hovenia dulcis Thunb. & $\begin{array}{l}\text { Uva-do- } \\
\text { japão }\end{array}$ & Rhamnaceae & 88 & 2.588 .235 & 1.192 .412 \\
\hline Laurus nobilis Linnaeus & Louro & Lauraceae & 3 & 0.882353 & 0.406504 \\
\hline Leucaena leucocephala (Lam.) R. de Wit. & Leucena & Fabaceae & 67 & 1.970 .588 & 9.078 .591 \\
\hline Ligustrum lucidum W.T.Ait. & Alfeneiro & Oleaceae & 96 & 2.823 .529 & 1.300 .813 \\
\hline Luehea divaricata Mart. & $\begin{array}{l}\text { Açoita- } \\
\text { cavalo }\end{array}$ & Malvaceae & 7 & 2.058 .824 & 0.948509 \\
\hline Malpighia glabra L. & Acerola & Malpighiaceae & 6 & 1.764 .706 & 0.813008 \\
\hline Mangifera indica L. & Manga & Anacardiaceae & 10 & 2.941 .176 & 1.355 .014 \\
\hline Maytenus aquifolia Mart. & $\begin{array}{c}\text { Espinheira- } \\
\text { santa }\end{array}$ & Celastraceae & 1 & 0.294118 & 0.135501 \\
\hline Melia azedarach L. & Cinamomo & Meliaceae & 1 & 0.294118 & 0.135501 \\
\hline Michelia champaca L. & Magnolia & Magnoliaceae & 1 & 0.294118 & 0.135501 \\
\hline Mimosa bimucronata (DC.) O. Kutze & Maricá & Fabaceae & 4 & 1.176 .471 & 0.542005 \\
\hline Musa sp. & Banana & Musaceae & 46 & 1.352 .941 & 6.233 .062 \\
\hline Nectandra lanceolata Nees & $\begin{array}{l}\text { Canela- } \\
\text { amarela }\end{array}$ & Lauraceae & 20 & 5.882 .353 & 2.710 .027 \\
\hline Ocotea puberula (Rich.) Nees & $\begin{array}{l}\text { Canela- } \\
\text { guaiacá }\end{array}$ & Lauraceae & 2 & 0.588235 & 0.271003 \\
\hline
\end{tabular}


...Continuação

\begin{tabular}{|c|c|c|c|c|c|}
\hline Nome científico & $\begin{array}{c}\text { Nome } \\
\text { popular }\end{array}$ & Família & Quant. & DA & DR \\
\hline Parapiptadenia rígida (Benth.) Brenan & Angico & Fabaceae & 16 & 4.705 .882 & 2.168 .022 \\
\hline Persea Americana L. & Abacate & Lauraceae & 30 & 8.823 .529 & 4.065 .041 \\
\hline Peltophorun dubium (Spreng.) Taub. & Sibipiruna & Fabaceae & 1 & 0.294118 & 0.135501 \\
\hline Pinus sp. & Pinus & Pinaceae & 11 & 3.235 .294 & 1.490 .515 \\
\hline Prunus myrtifolia L.Urb. & $\begin{array}{l}\text { Pessegueiro } \\
\text {-bravo }\end{array}$ & Rosaceae & 6 & 1.764 .706 & 0.813008 \\
\hline Psidium cattleyanum Sabine & Araçá & Myrtaceae & 3 & 0.882353 & 0.406504 \\
\hline Psidium guajava L. & Goiaba & Myrtaceae & 7 & 2.058 .824 & 0.948509 \\
\hline Pyrus communis L. & Pêra & Rosaceae & 3 & 0.882353 & 0.406504 \\
\hline Rhododendron simsii Planch. & Azaléia & Ericaceae & 5 & 1.470 .588 & 0.677507 \\
\hline Ricinus communis L. & Mamona & Euforbiaceae & 60 & 1.764 .706 & 8.130 .081 \\
\hline Rubus sellowii Cham. \& Schltdl. & $\begin{array}{l}\text { Amorinha- } \\
\text { preta }\end{array}$ & Rosaceae & 25 & 7.352 .941 & 3.387 .534 \\
\hline Schinus terebinthfolius Raddi & Aroeira & Anacardiaceae & 16 & 4.705 .882 & 2.168 .022 \\
\hline $\begin{array}{l}\text { Solanum mauritianum Scopoli, Joannes } \\
\text { Antonius }\end{array}$ & Fumo-bravo & Solanaceae & 21 & 6.176 .471 & 2.845 .528 \\
\hline Syagrus romanzoffiana (cham.) glassman & Jerivá & Arecaceae & 1 & 0.294118 & 0.135501 \\
\hline Syzygium cumini L. & Jamelão & Myrtaceae & 2 & 0.588235 & 0.271003 \\
\hline Tipuana tipu. (benth.) kuntze & Tipuana & Fabaceae & 6 & 1.764 .706 & 0.813008 \\
\hline Trema micranta L. Blum. & Pau-pólvora & Cannabaceae & 1 & 0.294118 & 0.135501 \\
\hline Vernonia condensata Baker & Boldo & Asteraceae & 1 & 0.294118 & 0.135501 \\
\hline Total geral & & & 738 & & \\
\hline
\end{tabular}

Estudo realizado por Gorenstein et al. (2010) em fragmentos de mata ciliar dentro do Campus da Universidade Tecnológica Federal do Paraná no município de Dois Vizinhos, que fica localizado próximo a área de estudo obteve um índice de Shannon $\mathrm{H}^{\prime}=2.856$. Observamos que a diversidade foi menor, mas esta menor diversidade pode ser explicada justamente pela maior densidade do local. No entanto nos permite inferir que a diversidade encontrada tanto para a mata ciliar do Córrego Água turva, quanto para a mata dentro da universidade é uma diversidade adequada.

Martins (1991), afirma que o H'é um bom indicador da diversidade local e pode ser utilizado na comparação de diferentes tipologias em uma mesma área ou diferentes áreas com a mesma tipologia.

O índice de equabilidade de Pielou calculado foi de 0,79 , o que demonstra que há uma distribuição homogenia de indivíduos por espécie, o que acaba por influenciar no valor de diversidade obtido. O índice de equabilidade ou uniformidade de Pielou refere-se ao padrão e distribuição dos indivíduos entre as espécies. Seu valor pode apresentar uma amplitude de 0 (uniformidade mínima) a 1(uniformidade máxima) (RODER et al., 2009). Contudo, apesar de não ocorrer uma espécie dominante tem-se a dominância de espécies com potencial invasor, que acaba por prejudicar o ambiente. 


\section{CONCLUSÕES}

A mata ciliar do córrego Água turva, em Dois Vizinhos, PR, teve sua diversidade florística alterada, mas ainda assim, apresentou um bom índice de diversidade de Shannon $(3,25)$ e de equabilidade de Pielou $(0,79)$, o que demonstrou ser uma floresta homogênea e com grande diversidade, quando comparado a outras florestas da mesma região.

Entretanto, a diminuição da área de mata ciliar, provavelmente prejudicou a dispersão das espécies naturais destes ambientes, dando espaço a grande dispersão das espécies exóticas, que foram se adaptando a este ambiente e foram encontradas em grande quantidade no local, como por exemplo, os indivíduos da espécie Ligustrum lucidum.

Levando-se em consideração o grande número de espécies exóticas invasoras no local, é necessário um firme propósito de conservação das espécies nativas e da faixa de mata ciliar, realizando o manejo que vise à preservação da diversidade das espécies nativas e a erradicação de espécies vegetais exóticas e invasoras.

\section{REFERÊNCIAS}

ALVAREZ, C. A.; STAPE, J. L.; SENTELHAS, P. C.; de MORAES GONÇALVES, L. J.; SPAROVEK, G. Köppen's climate classification map for Brazil. Meteorologische Zeitschrift, Stuttgart, v. 22, n. 6, p. 711-728, 2013.

ARAÚJO, M.H. T.; CARDOSO-LEITE, E.; CHAGAS, E.P. Os Fragmentos Florestais Urbanos Do Campus da UNIFEOB (São João Da Boa Vista - SP): Uma Abordagem Qualitativa Como Proposta Para Conservação E Manejo. - Revista da Sociedade Brasileira de Arborização Urbana, Piracicaba, v. 4, n. 3, p. 49-68, 2009.

BAILLY, D.; FERNANDES, C. A.; SILVA, V. F. B.; KASHIWAQUI, E. A. L.; DAMÁSIO, J. F.; Wolf, M. J.; RODRIGUES, M. C. Diagnóstico Ambiental e Impactos sobre a Vegetação Ciliar da Microbacia do Córrego da Ponte, Área de Proteção Ambiental do Rio Iguatemi, MS. Revista em Agronegócios e Meio Ambiente, Maringá, v.5, n.2, p. 409-427, 2012.

BLUM, C. T.; BORGO, M.; SAMPAIO, A. C. F. Espécies exóticas invasoras na arborização de vias públicas de Maringá-PR. Revista da Sociedade Brasileira de Arborização Urbana, Piracicaba, v. 3, n. 2, p.78-97, 2008.

FERREIRA, D.A.C.; DIAS, H. C. T. SITUAÇÃO ATUAL DA MATA CILIAR DO RIBEIRÃO SÃO BARTOLOMEU EM VIÇOSA, MG. Revista árvore, Viçosa, v. 28, n. 4, p. 617-623, 2004.

FERREIRA, R. A.; NETO, A. O. A.; SANTOS, T. I.; SANTOS, B. L.; MATOS, E. L. NASCENTES DA SUB-BACIA HIDROGRÁFICA DO RIO POXIM, ESTADO DE SERGIPE: DA DEGRADAÇÃO À RESTAURAÇÃO. Revista árvore, Viçosa, v. 35, n. 2, p. 265-277, 2011. 
GORENSTEIN, M.R.; BECHARA, F.C.; ESTEVAN, D.A.; SGARBI, A.S.; GALLO, I.C. Estrutura e diversidade da comunidade arbórea na trilha ecológica da UTFPR, Campus Dois Vizinhos através do método de quadrantes. In: SEMINÁRIO: SISTEMAS DE PRODUÇÃO AGROPECUÁRIA - CIENCIAS AGRÁRIAS, ANIMAIS E FLORESTAIS - UTFPR CAMPUS DOIS VIZINHOS, 4.2010, Dois Vizinhos. Anais... Dois Vizinhos: Editora UTFPR, 2010. p.1-4

INSTITUTO AMBIENTAL DO PARANÁ - IAP. PORTARIA № 125, DE 07 DE AGOSTO DE 2009. Disponível em: <http://www.iap.pr.gov.br/arquivos/File/Legislacao_ambiental/Legisl acao_estadual/PORTARIAS/PORTARIA_IAP_125_2009_ESPECIES_EXOTICAS.pdf>.

Acessado em 4 de maio de 2015.

JUNG, P. H. Diagnóstico da mata ciliar e qualidade do solo nas margens do Córrego Água Turva na microbacia hidrográfica do Rio Jirau Alto, Dois Vizinhos - PR. 2013.103 f. Monografia (Engenharia Florestal) Universidade Tecnológica Federal do Paraná. Dois Vizinhos, 2013.

LACERDA, D. M. A.; FIGUEIREDO, P. S. Restauração de matas ciliares do rio Mearim no município de Barra do Corda - MA: seleção de espécies e comparação de metodologias de reflorestamento. Acta Amazonica, Manaus, v. 39, n. 2, p. 295-304, 2009.

MARTINS, F.R. Estrutura de uma floresta mesófila. $2^{\underline{a}}$ ed. Universidade estadual de Campinas: Campinas. (Série teses), 1991.

OLIVEIRA, A. N. de; AMARAL, L. L. do. Florística e fitossociologia de uma floresta de vertente na Amazônia Central, Amazonas, Brasil. Acta Amazônica, Amazonas, v. 34, n. 1, p. 21-34, 2004.

OLIVEIRA, F. L. R.; BIZ, S.; AMARAL, I. M. G.; BRUN, E. J.; BRUN, F. G. K. Composição florística como indicadora de status ambiental da praia artificial do município de Cruzeiro do Iguaçu-PR. In: CONGRESSO DE CIÊNCIA E TECNOLOGIA DA UTFPR - CÂMPUS DOIS VIZINHOS, 2012, Dois Vizinhos. Anais... Dois Vizinhos: Editora UTFPR, 2012. p. 1-10.

PINHEIRO, F.; RIBEIRO, J. R. Síndromes de dispersão de sementes em matas de galeria do Distrito Federal. In: RIBEIRO, J. F.; FONSECA, C. E. L.; SOUSA-SILVA, J. C. (Eds.). Cerrado: caracterização e recuperação de matas de galeria. Brasília: Embrapa, 2001. p.335-361.

RODER, R.; FILHO, A. F.; GALVÃO, F.; MACHADO, S. A. Comparação florística entre uma floresta ombrófila mista e uma vegetação arbórea estabelecida sob um povoamento de Araucaria angustifólia de 60 anos. Revista Cerne, Lavras, 15, n. 1, p. 101-115, 2009.

ROSA, A. G.; SCHIAVINI, I., Estrutura da comunidade arbórea em um remanescente florestal urbano (Parque do Sabiá, Uberlândia, MG). Bioscience Journal, Uberlândia, v. 22, n. 1, p.151-162, 2006.

SAMPAIO, A. C. F.; ECKER, A. E. A.; MARANGONI, C. J. M.; FIORESE, L. M. R.; SORDI, E. A. Espécies exóticas invasoras na arborização de vias públicas de três bairros de Campo Mourão - PR. Campo Digit@I, Campo Mourão, v. 6, n. 1, p. 31-43, Campo Mourão, 2011.

SANTANA, O. A.; ENCINAS, J. I. Levantamento das espécies exóticas arbóreas e seu impacto nas espécies nativas em áreas adjacentes a depósitos de resíduos domiciliares. Revista Biotemas, Santa Catarina, v. 21, n. 4, p. 29-38, 2008. 
SCHALLENBERGER, L. S.; MACHADO, G. M. INVENTÁRIO DA ARBORIZAÇÃO NA REGIÃO CENTRAL DO MUNICÍPIO DE MANGUEIRINHA - PR. - Revista da Sociedade Brasileira de Arborização Urbana, Piracicaba, v.8, n.1, p. 54-64, 2013.

SOUZA, M. C.; MONTEIRO, R. Levantamento florístico em remanescente de floresta ripária no Alto Rio Paraná: Mata do Araldo, Porto Rico, Paraná, Brasil. Acta Scientiarum Biological Sciences, Maringá, v. 27, n. 4, p. 405-414, 2005.

SOUZA, J. A. N.; RODAL, M. J. N. Levantamento florístico em trecho de vegetação ripária de caatinga no Rio Pajeú, Floresta/Pernambuco-Brasil. Revista Caatinga, Mossoró, v. 23, n. 4, p.54-62, 2010.

VIGILIATO, G. R.; ZAMPAR, R. Susceptibilidade das zonas de recuperação de uma unidade de conservação à invasão biológica por espécies arbóreas exóticas. Revista de Saúde e Biologia, Campo Mourão, v. 6, n. 3, p. 25-37, 2011.

ZALBA, S. M. Introdução às Invasões Biológicas - Conceitos e Definições. In: BRAND, K. et al. América do Sul invadida. A crescente ameaça das espécies exóticas invasoras. Cape Town: Programa Global de Espécies Invasoras - GISP, p. 4-5, 2006. 